\title{
COMMENTARY
}

\section{Too cold may not be so cool: spontaneous hypothermia as a marker of poor outcome after cardiac arrest}

\author{
Jakobea Wörner and Mauro Oddo* \\ See related research by den Hartog et al., http://ccforum.com/content/14/3/R121
}

\begin{abstract}
In a recent issue of Critical Care, den Hartog and colleagues show an association between spontaneous hypothermia, defi ned by an admission body temperature $<35^{\circ} \mathrm{C}$, and poor outcome in patients with coma after cardiac arrest (CA) treated with therapeutic hypothermia (TH). Given that TH alters neurological prognostication, studies aiming to identify early markers of injury severity and outcome are welcome, since they may contribute overall to optimize the management of comatose CA patients. This study provides an important message to clinicians involved in post-resuscitation care and raises important questions that need to be taken into account in future studies.
\end{abstract}

den Hartog and colleagues prospectively analyzed data from 105 consecutive comatose patients resuscitated from cardiac arrest (CA) and treated with therapeutic hypothermia $(\mathrm{TH})$ over a 2-year period [1]. They observed that the percentage of patients with unfavourable outcome (including death, vegetative state and severe disability) was significantly higher in patients with spontaneous hypothermia (69\%) than in those with a body temperature $\geq 35^{\circ} \mathrm{C}$ on admission to the ICU $(50 \%$, $P=0.05)$. Using multivariable analysis, and adjusting for age, initial arrest rhythm, and APACHE II and SOFA scores, the association between spontaneous hypothermia and outcome at 6 months was confirmed.

In this single centre prospective cohort of more than 100 patients, spontaneous hypothermia remained

*Correspondence: mauro.oddo@chuv.ch

Department of Intensive Care Medicine, Lausanne University Hospital (Centre Hospitalier Universitaire Vaudois), Rue du Bugnon 46, 1011, Lausanne, Switzerland significantly associated with long-term outcome, even when adjusted for APACHE II and SOFA scores. This indicates that low body temperature $<35^{\circ} \mathrm{C}$ on admission after CA is a strong marker of neurological recovery.

Previous studies have shown that spontaneous hypothermia is associated with increased mortality after severe trauma and haemorrhage [2]. TH has improved prognosis of hypoxic-ischemic encephalopathy [3], and might have an impact on our ability to predict final patient prognosis [4]. den Hartog and colleagues identify spontaneous hypothermia as a new prognostic marker of CA.

However, in accordance with Utstein's style registry [5], arrest conditions (that is, witnessed versus un-witnessed arrest), initial arrest rhythm (that is, ventricular fibrillation versus non-ventricular fibrillation) and duration of circulatory arrest (that is, time from collapse to return of spontaneous circulation) are other well-known predictors of prognosis [6]. These parameters, and particularly time to return of spontaneous circulation, were not entered in the logistic regression; thus, it remains to be further established whether spontaneous hypothermia is an independent predictor of outcome. Furthermore, body temperature may be difficult to measure precisely, and reasons for spontaneous hypothermia can be multiple: for example, CA occurring in cold environments may have better neurological recovery despite low admission body temperature [7]. Therefore, although admission body temperature is an important parameter and a marker of injury severity, it should not be considered alone to guide therapy.

Notwithstanding these limitations, which are well recognized by the authors, the findings by den Hartog and colleagues are important and indeed in line with previous trauma [2] and more recent post-CA [8] studies showing that spontaneous hypothermia is associated with higher mortality. Pathophysiological mechanisms may involve extended damage to specific brain areas leading to impaired thermoregulation [9], thereby establishing a plausible relationship between post-anoxic injury, 
impaired hypothalamic thermoregulation with spontaneous hypothermia, and unfavourable outcome. Nevertheless, it should be noted that previous studies predominantly described hyperthermia, instead of spontaneous hypothermia, as a result of hypothalamic damage [10].

This study may also help explain some recent clinical observations. In particular, it was recently shown that early cooling did not seem to translate into better outcome [11]. This is in contrast with the abundant experimental literature [12] and some recent clinical evidence $[13,14]$. However, spontaneous hypothermia may have been a major confounding factor of these studies. While animal studies are conducted in stable conditions, this may often not be the case in humans after CA. In such conditions, time to target temperature may not be a reliable parameter, unless it is corrected for baseline demographics, including admission body temperature.

In conclusion, the findings by den Hartog and colleagues identify spontaneous hypothermia as a new prognostic marker that may have an influence on neurological recovery from CA. Together with other wellknown outcome predictors [15], admission body temperature should therefore be included in the early assessment of comatose CA patients and will be an important variable to be taken into account in future studies.

\section{Abbreviations}

APACHE, Acute Physiology and Chronic Health Evaluation; CA, cardiac arrest; SOFA, Sequential Organ Failure Assessment; TH, therapeutic hypothermia.

\section{Competing interests}

The authors declare that they have no competing interests.

Published: 20 October 2010

\section{References}

1. den Hartog AW, de Pont AC, Robillard LB, Binnekade JM, Schultz MJ, Horn J: Spontaneous hypothermia on intensive care unit admission is a predictor of unfavorable neurological outcome in patients after resuscitation: an observational cohort study. Crit Care 2010, 14:R121.

2. Wang HE, Callaway CW, Peitzman AB, Tisherman SA: Admission hypothermia and outcome after major trauma. Crit Care Med 2005, 33:1296-1301.
3. Hypothermia after Cardiac Arrest Study Group: Mild therapeutic hypothermia to improve the neurologic outcome after cardiac arrest. N Engl J Med 2002, 346:549-556.

4. Rossetti AO, Oddo M, Logroscino G, Kaplan PW: Prognostication after cardiac arrest and hypothermia: a prospective study. Ann Neurol 2010, 67:301-307.

5. Langhelle A, Nolan J, Herlitz J, Castren M, Wenzel V, Soreide E, Engdahl J, Steen PA; 2003 Utstein Consensus Symposium: Recommended guidelines for reviewing, reporting, and conducting research on post-resuscitation care: the Utstein style. Resuscitation 2005, 66:271-283.

6. Oddo M, Ribordy V, Feihl F, Rossetti AO, Schaller MD, Chioléro R, Liaudet L: Early predictors of outcome in comatose survivors of ventricular fibrillation and non-ventricular fibrillation cardiac arrest treated with hypothermia: a prospective study. Crit Care Med 2008, 36:2296-2301.

7. Friberg $H$, Rundgren M: Submersion, accidental hypothermia and cardiac arrest, mechanical chest compressions as a bridge to final treatment: a case report. Scand J Trauma Resusc Emerg Med 2009, 17:7.

8. Lyon RM, Richardson SE, Hay AW, Andrews PJ, Robertson CE, Clegg GR: Esophageal temperature after out-of-hospital cardiac arrest: an observational study. Resuscitation 2010, 81:867-871.

9. Morrison SF, Nakamura K, Madden CJ: Central control of thermogenesis in mammals. Exp Physiol 2008, 93:773-797.

10. He Z, Yamawaki T, Yang S, Day AL, Simpkins JW, Naritomi H: Experimental model of small deep infarcts involving the hypothalamus in rats: changes in body temperature and postural reflex. Stroke 1999, 30:2743-2751; discussion 2751.

11. Nielsen N, Hovdenes J, Nilsson F, Rubertsson S, Stammet P, Sunde K, Valsson F, Wanscher M, Friberg H; Hypothermia Network: Outcome, timing and adverse events in therapeutic hypothermia after out-of-hospital cardiac arrest. Acta Anaesthesio/ Scand 2009, 53:926-934.

12. Krieger DW, Yenari MA: Therapeutic hypothermia for acute ischemic stroke: what do laboratory studies teach us? Stroke 2004, 35:1482-1489.

13. Kim F, Olsufka M, Longstreth WT Jr, Maynard C, Carlbom D, Deem S, Kudenchuk P, Copass MK, Cobb LA: Pilot randomized clinical trial of prehospital induction of mild hypothermia in out-of-hospital cardiac arrest patients with a rapid infusion of 4 degrees $C$ normal saline. Circulation 2007, 115:3064-3070.

14. Wolff B, Machill K, Schumacher D, Schulzki I, Werner D: Early achievement of mild therapeutic hypothermia and the neurologic outcome after cardiac arrest. Int J Cardiol 2009, 133:223-228.

15. ECC Committee, Subcommittees and Task Forces of the American Heart Association: 2005 American Heart Association Guidelines for Cardiopulmonary Resuscitation and Emergency Cardiovascular Care. Circulation 2005, 112(24 Suppl):IV1-203.

doi:10.1186/cc9270

Cite this article as: Wörner J, Oddo M: Too cold may not be so cool: spontaneous hypothermia as a marker of poor outcome after cardiac arrest. Critical Care 2010, 14:1002. 